\title{
La Rambla de Barcelona: territorio en disputa Los vendedores ambulantes y la lucha por la ciudad
}

\author{
La Rambla de Barcelona: territory in dispute \\ Street vendors and the struggle for the city
}

Horacio Espinosa Zepeda*

Citar este artículo como: Espinosa Zepeda, H. (2019). La Rambla de Barcelona: territorio en disputa. Los vendedores ambulantes y la lucha por la ciudad. Revista Nodo, 13(26), pp. 61-77

\section{Resumen}

La Rambla, una de las calles más famosas del mundo, es una vía peatonal en el corazón de la Barcelona histórica. Su trazo parte la Ciutat Vella en dos barrios, El Gótico y El Raval, tan distantes en origen social como cercanos en destino: la ciudad mercancía. En La Rambla confluyen los vicios y virtudes de ambos barrios. Por un lado el Gótico, parque temático del Medioevo catalán. Barrio de postín creado casi ex-profeso a lo largo del Siglo XX para otorgarle monumentalidad a esta ciudad del Mediterráneo, pero también para crear una identidad y una narrativa catalana en base a la arquitectura. Debe ser uno de los barrios más fotografiados del mundo. Por otro lado, el Raval. La bestia negra cuyo nombre original era "El chino". Tradicional escondite en el centro de la ciudad de todo lo que la burguesía no quiere ni ver: putas, chulos, yonkis, inmigrantes, pobreza. Desde siempre amenazado por procesos de limpieza social y en los últimos años, por la gentrificación.

Como una tenaza, en La Rambla confluyen turistificación y limpieza social, creando un caldo de cultivo, paradójico y explosivo, que ha hecho de este espacio el lugar central del conflicto entre diversos colectivos de trabajadores callejeros y el Ayuntamiento de Barcelona. Artistas callejeros, músicos, vendedores de cerveza, estatuas humanas, pero sobre todo "manteros", que es el tema que nos ocupa en este artículo, han sido perseguidos, chantajeados, cooptados, con el objetivo último de que dejen la calle o que al menos, se oculten y no le hagan "mala fama" a la perla del Mediterráneo. Migrantes africanos, senegaleses en su mayoría, los ambulantes se han organizado políticamente en un sindicato "sui generis" como una manera de hacer visible su situación y defender sus derechos. Este trabajo de carácter exploratorio estudia el acto de "poner" una manta en el suelo como un tipo particular de cultura material que entrecruza objetos, infraestructuras urbanas, símbolos, formas de sociabilidad y organización política "a nivel de calle".

Palabras clave: Espacio Público, Barcelona, Trabajo informal, Urbanismo neoliberal, Turistificación, Sindicalismo popular

Fecha de recepción: 10 de abril de 2019 • Fecha de aceptación: 25 de mayo de 2019

* Doctor en Psicología social por la Universidad Autónoma de Barcelona. Observatorio de Antropología del Conflicto Urbano (OACU). Correo electrónico: horacio.espinosa.zepeda@gmail.com 


\section{Abstract}

La Rambla, one of the most famous streets in the world, is a pedestrian street in the heart of historic Barcelona. It's trace separates Ciutat Vella district in two Gótico and Raval. Those neigbourhoods stand side by side as distant in social origin as near at destination: the merchandise city. In La Rambla vices and virtues of both converge. On one hand the Gothic, theme park of Catalan Middleages. It's a kind of simulacrum created almost ex-profeso throughout the twentieth century to add monumentality to this Mediterranean city, but also to create a Catalan identity and a narrative based on architecture. It must be one of the most photographed neighborhoods in the world. On the other hand, Raval. The urban black beast, whose original name was "El Chino". Traditional hiding place in the center of the city with everything that bourgeoisie does not want to see: whores, pimps, junkies, immigrants, poverty. Always threatened by processes of social cleansing and in recent years, by gentrification.

Like pincers, in La Rambla turistification and social cleansing come together, creating a breeding ground, paradoxical and explosive, which has made this space the central place of the conflict between various groups of street workers and the Barcelona City Council. Street artists, musicians, street beer vendors, human statues, but above all "manteros", which is the subject that occupies us in this article, have been persecuted, blackmailed, co-opted, with the ultimate goal of expelling them out of the streets or at less hide them. African migrants, mostly Senegalese, those street vendors have organized themselves politically into a "sui generis" union as a way to make their situation visible and defend their rights. This exploratory work studies the act of "putting" a blanket on the ground as a particular type of material culture that crisscrosses objects, urban infrastructures, symbols, forms of sociability and political organization "at the street level".

Keywords: Public Space, Barcelona, Informal work, Neoliberal Urbanism, Touristification, Popular syndicalism

\section{Introducción}

A partir de los atentados terroristas en Barcelona del 17 de Agosto del 2017 se reeditó un género periodístico/literario de larga historia: las elegías a La Rambla. La Rambla bohemia, popular, burguesa, revolucionaria... todas salieron a la luz, como una manera de salir del shock, hablar de la belleza para olvidar el horror. Sin embargo, la realidad es que La Rambla en las últimas décadas está muy lejos de ser ese espacio común y transversal que nos gusta imaginar. Muy en el pasado han quedado esas imágenes románticas y romantizadas de la gente sentada en sillas de paja o posteriormente de metal, que se alquilaban a lo largo de toda La Rambla. Desde esa sillas, la gente miraba a otros que, como ellos mismos, iban con la misma intención a Las Ramblas: disfrutar del maravilloso espectáculo de la sociedad contemplándose a sí misma. El 20 de Agosto del 2000 desaparecería para siempre este servicio que con algunas interrupciones se había mantenido desde el siglo XVIII. Un curioso mobiliario urbano que no solo fue testigo sino en ocasiones actor mismo de la historia popular.

Tal como relata Ricard Valentí:

Además de ser testigos de los diferentes sucesos acaecidos en el centro de la ciudad, a menudo este mobiliario se convirtió en objeto de mira en manifestaciones obreras y revueltas sociales, pues en esas circunstancias era habitual usarlas para hacer barracones o lanzarlas contra las autoridades policiales (2013).

También romántica, aunque más peligrosa y canalla, pero igualmente perdida para siempre, se encuentra La Rambla que filmaron cineastas como Ventura Pons, quién inmortalizó en su "retrato intermitente", la figura de Ocaña, travesti y revolucionario. Ícono de la Barcelona post-franquista. Y junto con Ocaña, también elevó a status de leyenda a otros tantos personajes del barrio del Raval y del Gótico. Personajes cuya breve pero intensa vida significó la chispa de ese incendio que llegó a ser Barcelona, y por supuesto, La Rambla. Por que lo que le pasa a una le pasa a la otra. Y durante los 
años setenta y ochenta, La Rambla fue la arteria circulatoria que conectaba entre sí a la Barcelona "contracultural" y "punk". ¿Fue real o imaginada la Negra Flor con la que Santiago Auserón deseaba encontrarse al final de La Rambla? No sería raro que los versos de "Escuela de calor", también del líder de Radio Futura, hayan sido igualmente una ensoñación dedicada a La Rambla de los años ochenta: "Arde la calle, al sol del poniente, hay, tribus ocultas cerca del río, esperando que caiga la noche, hace falta valor..."

¿Una calle en llamas?, ¿tribus acechando?, es posible entenderlo por que podemos aún imaginarlo, pero entre tanto guiri, puestos de waffles y entradas VIP al museo del F.C. Barcelona, cuesta creer que haya sido real y no una fantasía literaria. La mercantilización de la ciudad ha hecho de La Rambla una procesión sin fin de turistas que hacen del "corazón de Barcelona" un sitio invivible e incluso intransitable. Los grupos de turistas que se agolpan en masa crean un muro de cuerpos que han transformado el apacible paseo en una calle con tráfico bípedo, embotellamientos incluidos. Haciendo de La Rambla una especie de gran Avenida peatonal de dos vías: desde el mar, descargados por los cruceros, los turistas van en línea recta como zombies hacia los centros comerciales de la Plaza Cataluña y desde estos centros comerciales de nuevo hacia el puerto. La Rambla hoy en día no es más que un muro de cuerpos que los habitantes de esta ciudad no nos atrevemos a cruzar, a menos que sea estrictamente necesario.

Para intentar revertir que La Rambla se convierta en una especie de no-lugar, mero pasadizo comercial entre el Maremagnum y la Plaza Cataluña, se dan 50.000 euros de subvención al Tast a la Rambla, una feria gastronómica que utiliza durante cuatro días La Rambla a lo largo y ancho. Esta feria, celebrará su quinta edición el año 2019, pero en el año de su lanzamiento y en una tónica discursiva de la tan en boga "recuperación de espacios públicos", la concejala de Ciutat Vella, Gala Pin, declaraba que la subvención otorgada al Tast a la Rambla "es un retorno que debe ayudar a recuperar espacios para

\section{A la privatización del espacio urbano se le suma la limpieza social de aquellos colectivos que aparecen como indeseables para la opinión pública y que dan "mala imagen" a la ciudad, caso ejemplar de esta estigmatización lo representan los manteros.}

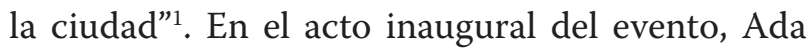
Colau afirmaba que "es el único acto del año organizado por la colectividad civil, siendo los propios vecinos y vecinas los que consiguen reconvertir La Rambla en un paseo ciudadano"2.

Sin embargo, la supuesta reconversión ciudadana de La Rambla a partir de proyectos como Tast a la Rambla no es más que un espaldarazo a la privatización del paseo. Claro está, en nombre de un vaporoso "espacio público" de significante escurridizo. Se trata de un acto de promoción del turismo reinvirtiendo en el ramo una tasa turística que, de forma paradójica, fue creada para amortizar el gasto público en infraestructura y servicios, producto de la misma avalancha turística a la que ahora se le da alas. Todo un caso del "pez que se muerde la cola".

A la privatización del espacio urbano se le suma la limpieza social de aquellos colectivos que aparecen como indeseables para la opinión pública y que dan "mala imagen" a la ciudad, caso ejemplar de esta estigmatización lo representan los manteros. Así, en el puerto de Barcelona, a la altura de La

1 Belén Parra. "Barcelona destinará 50.000 euros de la tasa turística para subvencionar el Tast de La Rambla”. El Mundo. 25 de Mayo del 2016.

2 Yaiza Saiz. "Arranca 'Tast a la Rambla', la fiesta gastronómica de Barcelona”. La Vanguardia. 9 de Junio del 2016. 


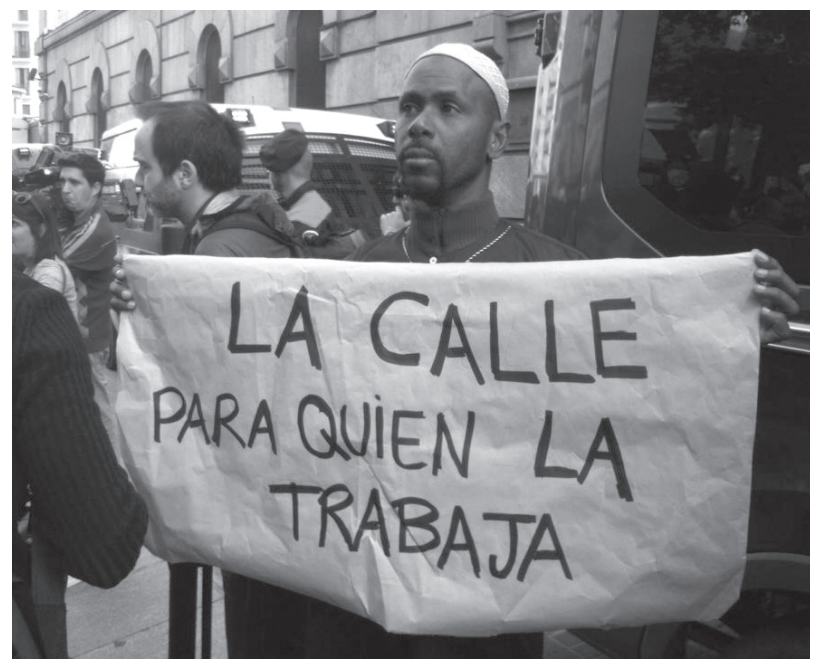

Figura 1. Calle, trabajo y resistencia. Fuente: propia

Rambla, donde se encuentra el centro comercial Maremagnum se materializa una de las tantas fronteras urbanas con las que se enfrenta este colectivo. Durante las noches de verano, que son las más rentables para los manteros, se forma un cordón de seguridad de la policía portuaria para impedir su paso. Los manteros, con sus pesados bultos, aguardan el momento en que los policías "les permitan" pasar a una explanada que se encuentra a un costado del paseo Colón justo antes del puente que va directo al Maregmanum. La imagen de la policía portuaria impidiendo el paso a un sitio público, mientras los manteros esperan con más o menos impaciencia, hasta que se de el momento de pasar e instalarse, genera una tensión similar a la que hay en la frontera amurallada de Melilla. El llamado espacio público "de todos" revela su falsedad: cada día una nueva frontera urbana, cada día un nuevo salto de la valla ${ }^{3}$.

Pero así como el neohigienismo, la mercantilización de la ciudad y la turistificación tiene en La Rambla uno de sus escenarios apoteósicos, esta centenaria calle también ha sido en innumerables ocasiones testigo de actos de resistencia popular. El viernes 2 de Octubre de 2015 tuvo lugar uno de esos actos, ya que nacía en Barcelona el Sindicato Popular de Vendedores Ambulantes. El acto de fundación se

3 Diario de Campo, 26 octubre 2016. llevaría a cabo en el centro de arte Santa Mónica, ubicado precisamente en La Rambla, a la altura de Drassanes. El Sindicato sería fundado por cerca de 80 manteros, en su gran mayoría de origen senegalés ${ }^{4}$. Esta es una fecha clave en la organización de la resistencia contra la persecución y criminalización de la venta callejera. El Sindicato nacería al amparo del Espacio del Inmigrante ${ }^{5}$, un colectivo popular y autogestionado de apoyo y movilización política a favor de los derechos de las y los migrantes ubicado en el Barrio del Raval.

El presente texto extrae solo una parte muy pequeña de mis observaciones de campo y prácticamente nada de las historias de vida que realicé con los manteros. Sobre todo me enfoco en describir algunas de las situaciones que viví en el espacio de La Rambla, en especial aquellas referentes a la disputa por el Espacio Público. Una parte de esa disputa es la lucha cotidiana que se vale de tácticas político-materiales de apropiación del espacio; otro aspecto de la lucha es el conflicto político institucional entre el Ayuntamiento de Barcelona y el Sindicato de Manteros; se trata de un asunto muy complejo que se describe someramente. Es necesario aclarar que los manteros, sobre todo aquellos que se organizan políticamente en torno al Sindicato, suelen encontrarse en el "ojo del huracán” de los medios e instituciones locales. Por este motivo, he decidido garantizar el anonimato de mis informantes falsificando algunos aspectos que podrían ayudar a la identificación de los actores, como sus nombres verdaderos.

$4 \quad$ Véase Periódico Diagonal, 6 octubre 2015.

$5 \quad$ Surgido en enero del 2013, El espacio del inmigrante es un colectivo formado a partir de la ocupación de un edificio vacío, que pasará a llamarse "el Hotel del Raval", situado en el pasaje de Bernardí Martorell. Este Inmueble acogerá espacio para vivienda y paulatinamente se irá conformando como Centro Social. Paralelamente a la ocupación del edificio, un grupo de profesionales indignados con el real decreto conocido como "apartheid sanitario" proponen a la asamblea del nuevo inmueble abrir un punto de atención medica para inmigrantes. Un par de años después es en este espacio donde van a surgir las primeras iniciativas que germinarían en la creación del Sindicato Mantero de Barcelona. 


\section{La utopía destructora del urbanismo neoliberal}

Para Marshall Berman la experiencia de ser modernos es esencialmente trágica en tanto promesa de una vida más intensa, nueva a cada momento y de constante "progreso" que sin embargo se cimenta en la destrucción de formas de vida que estorban a su proyecto: "nos arroja a todos en una vorágine de perpetua desintegración y renovación, de lucha y contradicción, de ambigüedad y angustia" (Berman, 1982, p. 1).

Parte consustancial de la modernidad capitalista es que innovación y destrucción vayan de la mano en el mantenimiento del sistema o como dijese el propio Berman citando a Marx: "todo lo sólido se desvanece en el aire". Schumpeter, en extraña sintonía con el marxismo para ser un teórico del libre mercado, propondría el concepto de "destrucción creativa" como "hecho esencial del capitalismo" (Arrighi, 1994, p. 392). No obstante, si para Schumpeter, la destrucción (urbana, medioambiental, humana...) que genera el capitalismo, se podría describir como un mal necesario en la consecución de la innovación y el progreso, para Marshall Berman es justo lo contrario: se crea para poder seguir destruyendo y es el ciclo interminable de destrucción lo que hace girar la rueda del capital (Berman, 1982, p. 95).

En el caso de Barcelona, para entender los procesos urbanos de "destrucción creativa" actuales hay que remontarse bastante atrás en el tiempo, hasta el siglo XIX como menos, cuando se llevó a cabo el plan urbanistico de Ildefons Cerdá, uno de los padres del urbanismo moderno. Inicialmente, el plan ideado por Ildefonso Cerdá denominado Proyecto de Reforma y Ensanche de Barcelona (Fernández, 2014, pp. 27-32), fue elaborado como respuesta al problema de la superpoblación de la ciudad vieja encerrada dentro de sus murallas. Enmarcandose dentro de la ideología higienista de su maestro parisiense, el Barón Haussman, Ildefons Cerdá planearía la apertura de al menos tres grandes vías en el centro de la ciudad, tres espadas con las que se pretendía destripar el centro histórico. Destruir para salvar, podría sintetizarse la ideología higienista. O como le llamo a propósito del neohigienismo contemporáneo: una "violencia virtuosa” (Espinosa, 2017). El sueño era integrar la ciudad en un mismo esquema circulatorio conformado por el ensanche, el puerto y la ciudad antigua. En palabras del mismo Cerdá:

La abertura de estas grandes vías al través de la Ciudad antigua según las direcciones de los vientos más saludables, proporcionará ancho paso a la luz, al aire, a los hombres y a las mercancías, y traerá la salubridad, el bienestar y la riqueza a toda la población. Aumentando la prosperidad en todos los barrios para los cuales la mala disposición de las calles es hoy día una barrera para el Comercio y la circulación y vendrá a compensar e indemnizarles de los daños que han experimentado (Cerdá, 1859, p. 406).

Cerdá moriría llevando a cabo tan solo pequeñas intervenciones urbanas contenidas en su Proyecto. Sin embargo, gracias a él, el sueño de destripar la "insalubre" ciudad vieja quedaría marcado con fuego en las fantasías de la clase industrial y política de la ciudad. Este ansiada utopía parecía cercana cuando en noviembre de 1901 una formación que representaba a la burguesía catalana, los nacionalistas de la Lliga Regionalista ganaban las elecciones para el Ayuntamiento de Barcelona. Las élites regionales deseaban hacer de Barcelona la capital del Mediterráneo y estas aspiraciones no podían llevarse a cabo sin una gran obra urbanizadora que fuera capaz de ordenar y sanear la ciudad a la vez que regular el crecimiento suburbano de los pueblos agregados. Para llevar esto a cabo rescataron el Proyecto del Ensanche barcelonés de Cerdá. En el centro de los planes de hegemonía política del nacionalismo catalán se situaría la arquitectura y el urbanismo como lo explica perfectamente Agustín Cócola (2011).

Así, a principios del siglo XX se procedió a la apertura de una de las grandes vías proyectadas por Cerdá: la "Gran Via Laietana", que conecta el barrio pesquero de la Barceloneta con el 
Ensanche. Esta reforma comportó la destrucción de 2199 casas y muchos palacios medievales, afectando a unas diez mil personas (Cócola, 2011, p. 101). Un año después de los inicios de la apertura de la Via Laietana, en 1909 acaecerían los sucesos de la llamada semana trágica. No hay documentos que prueben la influencia de las reformas urbanísticas en el clima de descontento popular, pero no resultaría extraño imaginar que entre los exaltados e insurrectos se encontrasen muchos de aquella decena de miles que se vieron en la calle de la noche a la mañana.

La burguesía industrial, ante la necesidad de circulación, control e higiene destruiría el trazado urbano medieval y todos los edificios históricos que allí se encontraban. $\mathrm{Al}$ mismo tiempo, ante la necesidad de signos de identificación colectiva comenzaría a planificar la exhibición de su propia historia (Cócola, 2011, p. 20).

Con los escombros de las casas de los pobres destruidas por la construcción de la Via Laietana, reformarían el anteriormente conocido como "Barrio de la Catedral" y se inventarían un nuevo barrio de dudosa autenticidad rebautizado como "El Barrio Gótico". Este proceso se inició con la construcción de la fachada de la Catedral entre 1887 y 1912, y concluiría con la monumentaliza-

A partir de mediados de
los años ochenta, con la
nominación de la ciudad
condal como sede de los
Juegos Olímpicos del 1992,
se popularizaría el llamado
"Modelo Barcelona", el
cual, más que un plan de
desarrollo de infraestructura
debería entenderse como un
"laboratorio urbano y social".

ción historicista de todo el barrio que la rodea. Proceso de reforma y reconstrucción histórica que no terminó sino hasta ya con el franquismo en decadencia, en la década de los años 70 .

A partir de mediados de los años ochenta, con la nominación de la ciudad condal como sede de los Juegos Olímpicos del 1992, se popularizaría el llamado "Modelo Barcelona", el cual, más que un plan de desarrollo de infraestructura debería entenderse como un "laboratorio urbano y social" (Montaner, 1992). Es decir, un experimento donde la materia prima es la subjetividad de los propios ciudadanos. La metáfora de la ciudad como laboratorio urbano, a pesar de su glamour, es muy elocuente de la visión que se tiene de los ciudadanos en tanto cobayas adiestradas para ser "copartícipes de su propia dominación" (Delgado, 2016). Este nuevo urbanismo, operaría a partir de una serie de "actuaciones de acupuntura urbana" (Acebillo 1999, p. 230), a "escala humana" y con la intención de dotar a la ciudad de espacios públicos "de calidad".

Sin embargo, como han mostrado Giuseppe Aricó et al., una revisión crítica de este relato idílico, sustentado por la llamada "teoría de las etapas" del urbanismo barcelonés, nos devela cómo el aparentemente "nuevo" urbanismo no hace más que "salvaguardar" el "poder de clase" por parte de una "dinastía local" a través de intervenciones que apuntalan lo hecho en las "etapas" desarrollistas previas (Aricó et al. 2016, pp. 226-236). De esta manera, aunque se venda como un urbanismo "participativo", el plan de proyectar a Barcelona como un "centro de consumo y de servicios" no se ha modificado en décadas, haciendo de la ciudad no un lugar abierto y plural, sino perdurando en su objetivo de ser "un eslabón más en la cadena de extracción de plusvalías" (2016, p. 242).

En esta misma lógica, en los años más recientes, la ciudad de Barcelona se ha posicionado como referente en la aplicación de una reestructuración de la autoridad pública a través de innovadoras estrategias de fiscalización de la población, sustentadas de manera menos evidente en los 
tradicionales mecanismos represivos, para dar paso a una creciente gestión ciudadana a través de formas de control blando donde el urbanismo, la "educación cívica", ciertas aplicaciones tecnológicas, el marketing y el diseño juegan su propio rol para el control y la fiscalización urbanas. Son los años pre-olímpicos donde se habla de la edad de oro de este nuevo "urbanismo redentor" (Capel, 2006), que tendría la pretensión de ser un referente "democrático" frente al desarrollismo de la época tardo-franquista.

Sería necesario un libro entero para documentar todas las acciones de "acupuntura urbana" realizadas con el objetivo de higienizar socialmente espacios puntuales de la ciudad. Se me vienen a la mente unos cuantos ejemplos no exentos de creatividad en la gobernanza. Auténticos procesos de exclusión social a partir de intervenciones con apariencia de renovación urbana, dotación de equipamiento cultural/lúdico o estetización de los espacios públicos. Tan solo en lo que corresponde al Raval y al Barrio Gótico se puede mencionar la sala de lectura al aire libre en los Jardins Rubió i Lluch, proyecto que quiere disimular sin conseguirlo su intención de expulsar a los indigentes y yonquis que han sido sus usuarios habituales; la construcción de un parque infantil en el centro de la Plaza George Orwell conocida como "plaza del tripi" con el objetivo de desincentivar la ingesta de cervezas por parte de los jóvenes que se sentaban ahí a beber o el rediseño del alféizar de los ventanales del Can Ricart del Raval, dándoles forma de rampa descendente para evitar que los vecinos se sienten cómodamente a charlar como lo hacían habitualmente. Se podría elaborar un larguísimo catálogo de homeopáticas operaciones de urbanismo anti-social en el espacio público, que se ha transformado en los últimos años en un lugar hostil y "alérgico" a sus usuarios. Esto, paradójicamente, es lo que se entiende en el argot urbanístico como espacios públicos "de calidad".

Con la llegada al gobierno de Ada Colau se camuflan las acciones de control blando bajo una capa discursiva de regeneración ciudadana. Es resal-

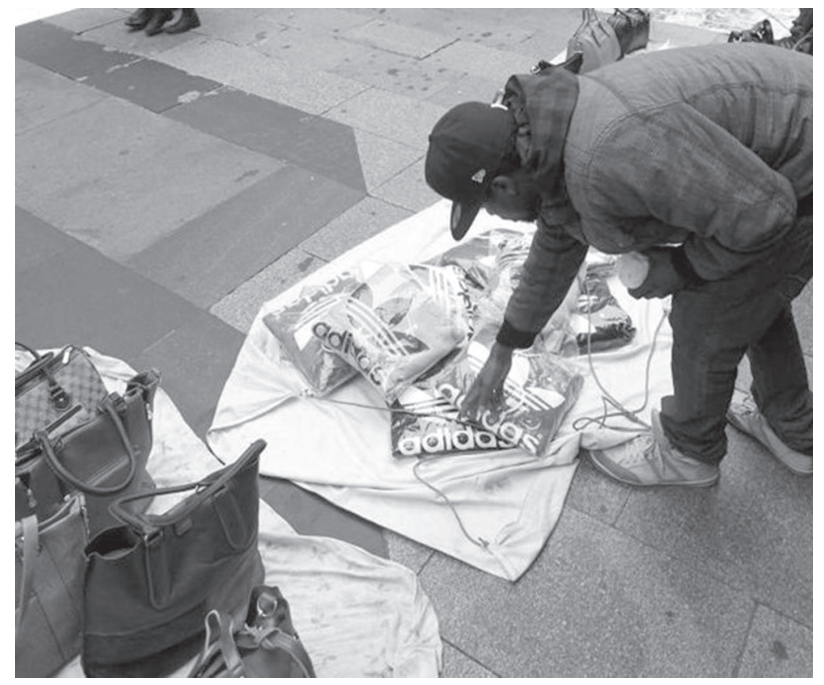

Figura 2. Comercio a ras del suelo. Fuente: Sergio González

table la ideología "ciudadanista" (Delgado 2016) que tiene como objetivo último "realizar empíricamente el proyecto cultural de la modernidad en su dimensión política, que entendería la democracia no como forma de gobierno, sino más bien como modo de vida y asociación ética" (Delgado 2011, p. 21). Este ciudadanismo subyace plenamente en el proyecto del gobierno de Barcelona En Comú6. En este discurso tiene una centralidad importante la sobrevaloración y simultáneo vaciamiento de contenido del llamado "espacio público", en el cual la demarcación territorial se encuentra asociada a un determinado vínculo social y se gesta un determinado sujeto político: el ciudadano. Se trataría de "lo topográfico cargado o investido de moralidad" (Delgado 2011, p. 19). Este urbanismo de baja intensidad, participativo y "ciudadano" funcionaría en parte como una manera de edulcorar las contradicciones generadas por un modelo neoliberal que desde sus orígenes se planteaba la explotación de las zonas rentables de la ciudad, como la ciutat vella.

El discurso que legitima e incluso eleva el espacio público a la categoría de "valor" está estructurado de tal manera que oculta a la vez que resuelve "mági-

6 Véase Seres Urbanos, diario El País, 15 de Agosto del 2016. 
camente" las contradicciones que se dan en él. Los conflictos sociales profundos que repetidamente se vuelven a presentar en la realidad práctica de espacios públicos concretos son presentados como consecuencia de determinadas fórmulas urbanísticas, y así mismo la solución de tales problemas "es vendida" como una "solución urbanística", cuando en origen se trata de un problema social.

\section{El Juego}

La primera vez que observé la estrambótica escena de un vehículo circulando a lo largo del paseo peatonal de La Rambla de Barcelona, fue mientras realizaba mi observación de campo con los manteros que se encontraban ahí mismo vendiendo sus productos ${ }^{7}$. Era la noche de Halloween del año 2016 y ante la atónita mirada de los turistas pintarrajeados de zombies o vampiros, presenciamos la escena de una furgoneta de la Guardia Urbana -"lechera" en el argot callejerocirculando en pleno paseo de La Rambla con la intención de echar a los manteros amenazándolos con ser atropellados. Los manteros ante la visión de "la lechera" se levantaban parsimoniosamente, levantaban sus mantas, tiraban de un cordón con el que pueden transformar su manta en un bulto, se la ponían al hombro y esquivaban "el golpe" de la furgoneta, colocándose nuevamente en otro punto de La Rambla, donde de nueva cuenta desplegaban su manta en el suelo. Esta escena se repitió una y otra vez durante toda la noche, en una extraña y surrealista danza urbana.

La última vez que tuve conocimiento de que un vehículo transitó por toda La Rambla, no fue por observación directa, sino por una trágica noticia que conmovió la ciudad: unos terroristas condujeron una furgoneta sobre el mismo paseo, pero ya

\footnotetext{
7 "Manteros" y "Top Manta", son las formas vernáculas de denominar a los vendedores ambulantes. La primera por la manta sobre la cual colocan su mercancía; la segunda haciendo un juego de palabras entre el mismo elemento de la manta y la, ahora un tanto anacrónica, venta de discos piratas con los éxitos del momento ("top").
}

no con la intención de intimidar, como la policía, sino de matar. Hablo del atropellamiento masivo ocurrido en La Rambla el 17 de Agosto del 2017 y que se saldó con más de un centenar de víctimas entre muertos y heridos. En aquella ocasión, cierta prensa nacional obcecada en señalar a Barcelona como el reino de la anarquía, intentaría inculpar al gobierno de Ada Colau por una supuesta permisividad y dejadez. Todo esto debido a las críticas por no haber colocado bolardos para la protección de La Rambla ante ataques terroristas con vehículos, previendo atentas por atropellamiento masivo como ya había ocurrido en otras ciudades europeas como el atentado de 2016 en Niza.

A raíz de lo sucedido, escribía junto con el antropólogo José Mansilla un artículo de prensa que intentaba "darle la vuelta" al tema de los bolardos en La Rambla ${ }^{8}$. Mi experiencia etnográfica me autorizaba a decir que los bolardos no habrían permitido realizar las funciones de control y vigilancia cotidiana de la policía, la cual solía subir vehículos a La Rambla con el objetivo principal de atemorizar manteros. Para que pudiesen entrar las patrullas en Las Ramblas era necesario que no hubiese bolardos, situación que aprovecharon los terroristas a escala criminal. Por lo tanto, más que por "permisividad", la desprotección de La Rambla era producto de los efectos secundarios del control urbano. Walter Benjamín mostró, en su análisis de la haussmanización del París decimonónico como el "embellecimiento estratégico" que echó por tierra los barrios populares parisinos tenía como objetivo último re-escribir la sinuosa traza de la ciudad histórica, tan llena de "obstáculos" urbanísticos poco favorables a la entrada de los carromatos militares (Benjamin, 1982, p. 94). No hay que olvidar que en esas callejuelas y callejones surgió la revolución popular de la comuna de París. Por lo tanto, era menester realizar grandes bulevares donde pudiesen circular las tropas y así reprimir cualquier acto de sublevación.

8 Véase El Diario.es, 24 de Agosto del 2017. 
Benjamin también intuyó que este urbanismo para el control social podría terminar siendo funcional con la, en esos momentos, aún incipiente economía de mercado: los ricos paseaban y compraban en lujosos pasajes, pero también realizaban inversiones inmobiliarias en un Paris libre de "pobres y piojosos". Esto se consiguió con la garantía dada por el Estado de que, ante cualquier brote de disconformidad, nada impediría el paso de las fuerzas garantes de "la ley y el orden". No es una suerte de libertinaje lo que hace que el urbanismo contemporáneo esté obsesionado con la accesibilidad y la movilidad, por el contrario, es el reino de la transparencia y la línea recta penetrante lo que lleva a diseñar ciudades "sin obstáculos". Este urbanismo de línea recta concebido exclusivamente para la circulación, ya sea de consumidores, capitales o trabajadores, ve en los manteros una amenaza a la realización de una utópica ciudad diáfana y libre de interrupciones, aunque siempre siguiendo el guión del ideal burgués de una ciudad y un espacio público pensado para las clases medias.

De hecho, este espacio público diáfano y "accesible" del urbanismo moderno es uno de los mayores reproductores de fronteras de clase, raza y/o género al interior de las mismas ciudades. A lo largo de La Rambla, los vendedores callejeros despliegan una serie de tácticas y estrategias, que ellos denominan "El Juego", para poder burlar, no siempre con éxito, a la represión policiaca. El Juego inicia desde el momento que salen de su casa, donde la policía ya los tiene identificados y vigilados. En algunas ocasiones han sido detenidos afuera de sus propios domicilios ${ }^{10}$ o simplemente no se les permite la entrada al metro, como en el caso de la prohibición de introducir bultos grandes al metro, una normativa ad hoc a la persecución del top manta ${ }^{11}$. Cuando logran superar la primera frontera, que es el acceso al transporte, se enfrentan a la disyuntiva de encontrar un sitio donde vender.

\footnotetext{
9 Entrevista a Abdou 02.05. 2016

10 Entrevista a Abdou 13.05. 2016

11 Véase Diario Izquierda, 20 de abril de 2016.
}

La última vez que tuve
conocimiento de que un
vehículo transitó por toda
La Rambla, no fue por
observación directa, sino
por una trágica noticia que
conmovió la ciudad: unos
terroristas condujeron una
furgoneta sobre el mismo
paseo, pero ya no con la
intención de intimidar, como
la policía, sino de matar.

A su inminente llegada a Las Ramblas el mantero tiene que averiguar, de una u otra manera, cual es el mejor sitio para instalar su manta. Para ello tiene que hacer una investigación y cerciorarse de la presencia de Guardia Urbana, Mossos d' Escuadra y policía secreta. Si hay "secretas" en Liceu, irá mejor a Plaza Cataluña o al revés. Si no se puede salir en ese momento a vender, el mantero esperara, adentro del metro, en los andenes, en las escaleras, en los alrededores, donde pueda. El siempre tendrá paciencia para esperar "el momento justo". $\mathrm{Su}$ supervivencia depende de ello, por lo tanto, no importa esperar; como dice Francesco Careri: "perdiendo el tiempo, se gana espacio"12.

Para Michel de Certeau, si la estrategia se constituye en "una victoria del lugar sobre el tiempo", la táctica, por el contrario, sería una victoria de la instancia "temporal": el aprovechamiento del acontecimiento. "La táctica es un arte del débil" (1980, p. 43) en tanto no posee un lugar de poder desde el cual aplicar una racionalidad. No siendo posible el aislamiento, la táctica implica hacer un

12 Francesco Careri. "Errare Humanum Est". Conferencia realizada en el Aula Magna de la Facultad de Geografia e Historia. Universidad de Barcelona. Campus Raval. Jueves 1 de Diciembre del 2016. 
uso del movimiento y del escamoteo de la mirada del control panóptico (1980, p. 84); hablamos de una puesta en escena de las "jugarretas", aquellas que los griegos conocían como metis o arte del fingimiento, del engaño, del olfato y el sentido de oportunidad (1980, pp. 90-91); pero también es un "arte de la memoria", una memoria no como acto de rememorar el pasado sino como memoria que "brilla con la ocasión", que es presencia en "la pluralidad de tiempos" (1980, pp. 92-93). Y es que la táctica no archiva lo escrito, su práctica es reescritura y como en la danza, piensa al hacer: "El relato no expresa una práctica. No se limita a expresar un movimiento. Lo hace. Se le comprende si se entra en el baile" (1980, p. 90).

Los manteros, en cierto sentido, están "condenados" a las tácticas. Incluso su hogar no es un "lugar propio", como demuestra el acoso de la policía a las puertas de sus casas. Ellos no tienen el poder de aislarse y delimitar un territorio sino que se ven obligados a hacer uso de esos lugares dominados por otros, los poderes sobre la ciudad. La táctica del mantero implica un constante movimiento para poder escamotearse de la mirada del control panóptico; pero también hace uso de las "jugarretas", aquellas que los griegos conocían como metis o arte del fingimiento, del engaño, del olfato y el sentido de oportunidad. Táctico es el uso del "ambu" (bulto) transformado con un movimiento hábil, en un "sare" (manta), como se diría en idioma wolof $^{13}$.

El espacio creado por el mantero, es una instancia circunstancial, temporal y polivalente. $\mathrm{Su}$ propiedad no está determinada ya que ésta se define a través de sus prácticas. El mercadillo es espacio que emerge con la ocasión y a la inversa, es una ocasión constituida que se da en el lugar adecuado. En términos contemporáneos, diríase que se trata de un espacio "performativo" (Butler 1993), que solo existe en tanto es practicado. El urbanismo táctico del mantero podría ser descrito como el "espacio vívido" de Henri Lefebvre (1974,

13 Demba 10.05.2016 p. 93), es decir, el "espacio social" o aquel que "incorpora los actos sociales, las acciones de los sujetos tanto colectivos como individuales que nacen y mueren, que padecen y actúan."

El mantero con su pesado y voluminoso ambu sobre la espalda, espera el momento oportuno, para desplegarlo y transformarlo en un sare. Si la policía o un secreta viene, el sare vuelve a transformarse en ambu gracias a un mecanismo que tiene la capacidad de territorializar y desterritorializar: un cordón que al ser tirado cierra toda la mercancía en su interior de manera automática y que permite al mantero, si es necesario, salir corriendo o lo contrario, instalarse para vender en cuanto se ve la mejor oportunidad. Este urbanismo táctico desplegado por los manteros se contrapone al modelo institucional de ciudad pensada "de arriba hacia abajo". Se trata de un urbanismo vivo, fluctuante e inestable. Pero sobre todo, político.

\section{La Rambla: ¿Un espacio para todos?}

Lola López, Comisionada de Inmigración, Interculturalidad y Diversidad de Barcelona dijo en una entrevista que "permitirle la venta ambulante ilegal a los manteros sí sería una política racista"14 respondiendo a las críticas que se han lanzado al Ayuntamiento por la persecución de los manteros. Probablemente sin ser consciente de ello, la argumentación y la lógica de la funcionaria sobre la persecución a los manteros se encontraba más cercana al clasismo que a la protección en contra de una discriminación positiva. Específicamente respondía a una de las formas manifiestas del clasismo como es el rechazo antes que a los pobres a "lo pobre", en particular a sus "formas de trabajo", a sus "formas de vida" y a las culturas con las que se le relaciona. Owen Jones (2011) lo describe bien como la demonización de una clase social.

14 Véase El Diario, 16 septiembre 2016. 
La lógica de si no te persigo te estoy discriminando es perversa. Esta es bien conocida por otros colectivos, como por ejemplo, las prostitutas de calle. $\mathrm{Al}$ encontrarse fuera del marco regulatorio, realizando una actividad altamente estigmatizada, las cuales aunque trabajen de forma independiente se encuentran irremediablemente relacionadas con el tráfico sexual (al igual que a los manteros se les estigmatizará vinculándolos con el contrabando), o en el "mejor" de los casos como "víctimas" antes que como sujetos con agencia. Las prostitutas, fuera del marco regulatorio y siendo explotadas por vivir en una sociedad de mercado, cuando las instituciones las persiguen para "protegerlas", estigmatizan su actividad. Como estrategia se esconden, precarizando sus condiciones de trabajo y seguridad.

Carlos Delclós (2016) respondiendo al comentario de la comisionada de inmigración de Barcelona, escribiría un texto donde describe "la incapacidad de la izquierda para gestionar la economía informal". Este sociólogo señalaba el error que presupone, sobre todo viniendo de un gobierno de "izquierda", el no reconocer el carácter "de clase" de un instrumento político como el Sindicato Popular de Vendedores Ambulantes de Barcelona creado por los manteros, a los cuales "pocos dudarían en considerar como desposeídos" (Delclós 2016). En otro medio, a través de una carta abierta dirigida a la comisionada, Julián Porras y yo mismo coincidíamos con Delclós en el carácter ya no solo clasista sino también fiscalizador, de las políticas regulatorias de la informalidad en Barcelona, donde este comentario sería solo una muestra más o menos mediatizada ${ }^{15}$.

A través de ambiciosas estrategias de marketing, Barcelona ha asumido su identidad de gran escaparate, "la millor botiga del mon" (la mejor tienda del mundo $)^{16}$ reza uno de sus eslóganes más famosos

15 Véase Periódico Diagonal, 28 de septiembre de 2016 y 11 de noviembre de 2016, reflexiones que son en cierta medida el borrador de muchas de las ideas contenidas en el presente texto.

16 Véase El País, 3 marzo 2007. creado durante el gobierno socialista del llamado tripartito. En el contexto de una economía, en gran parte sustentada en la espectacularización de la ciudad, la imagen urbana juega un rol desproporcionadamente importante, por lo que las ordenanzas públicas han generado normativas y/o intervenciones que generan exclusión social por razones "cosméticas", disfrazadas de promoción de la urbanidad. Tal es el caso de la conocida coloquialmente como "Ordenanza Cívica” y por la cual se rigidizó el uso del espacio público, generando un enorme abanico de limitaciones al libre uso de la ciudad, sobre todo de aquellos que usan la calle como medio de subsistencia.

A pesar de que durante su campaña la alcaldesa Ada Colau prometió derogar la "Ordenanza de medidas para fomentar y garantizar la convivencia ciudadana", promulgada por el entonces Alcalde Xavier Trías en 2006, para el 2019 la derogación seguía sin ocurrir. Por el contrario, circularía el borrador de la nueva "Ordenanza de usos ciudadanos del espacio público" sustituto de aquella, y en plena campaña para las elecciones municipales, el gobierno de Colau parece que habría rebajado la apuesta presentando una propuesta de normativa simplemente "retocada". En una lectura general del texto, tristemente se podía comprobar que se trata de una ordenanza totalmente continuista con la de Trías. Por supuesto, que la norma sea continuista no implica que su aplicación se vaya a cumplir "a raja tabla", para evaluar eso, habría que esperar a su implementación.

La única novedad, en todo caso, sería la inclusión de varios apartados referentes a combatir "el sexismo y el machismo en el espacio público"; por ejemplo la tipificación del "acoso sexual" a las mujeres como falta grave y castigado con hasta 2,000 euros. Sin embargo, en el contexto de una normativa que vulnera aún más a los más vulnerables, nos entra la duda de si se trata de un caso más de "purplewashing"17, es decir, de la instrumen-

17 Para la escritora feminista Brigitte Vasallo el "purplewashing" podría definirse como "el proceso de instrumentalización 


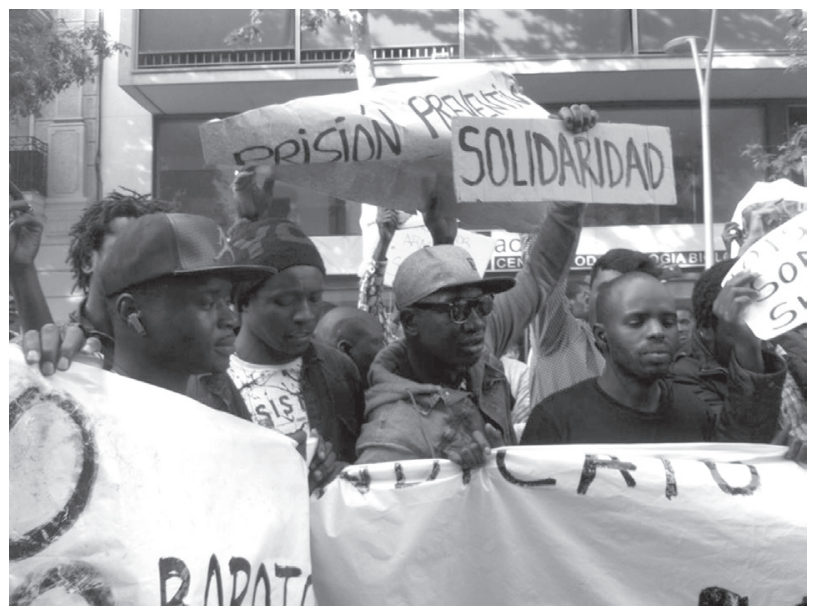

Figura 3. La calle es nuestra. Fuente: propia

talización del discurso de género por parte del Ayuntamiento para dotar de un barniz "progre" a una norma que conserva su carácter excluyente, moralizante, privatizador y clasista.

En la nueva ordenanza se insiste una y otra vez en los tópicos respecto al espacio público como un lugar donde se debe salvaguardar "la circulación" (Artic. 5/3), la "tranquilidad" (Artic 6-2/D) así como "el tránsito" y "la accesibilidad" (Artic $8-2 / \mathrm{M})$; es decir, se mantiene una visión liberal del espacio público como lugar de paso y no como lugar de uso, encuentro y sociabilidad. ¿Hasta cuando se reconocerá no solo el derecho a la movilidad sino también el derecho a la inmovilidad?, es decir nuestro derecho a hacer de la calle un espacio no instrumental sino de vida. Los artículos y normas que penalizan o regulan el "bloqueo" al tránsito de personas son muchísimos. Se penaliza sentarse en la vía pública y en el caso del consumo de bebidas alcohólicas en la calle (que no está explícitamente prohibido), se penaliza indirectamente en el caso de que su consumo "produzca aglomeraciones", por lo que más que ser anti-alcohol, se trataría de una norma hostil con la apropiación espontánea del espacio público. ¿Se puede hablar de una ordenanza que quiere garantizar "el derecho a la ciudad" de los

de las luchas feministas con la finalidad de legitimar políticas de exclusión". Ver: diario El Confidencial. 03/04/2016. ciudadanos cuando se prohíbe el libre uso de la calle?

Lo que niega el derecho a la ciudad de las personas no es el comportamiento incívico sino la mercantilización de la ciudad. En este caso, el asunto de la bebida es ejemplar: en el fondo, no es que se prohíba beber en la calle sino que se prohíbe beber en la calle sin pagar. Aquí el Ayuntamiento hace las veces de segurata que se encarga de que nadie "introduzca bebidas en el espacio público" cuya titularidad es otorgada de facto a las terrazas de los bares.

Pero la ordenanza también tira de pedagogía ciudadanista, intentando "civilizar" a través de la "elevación" del espacio público al status de territorio investido de moral. En este sentido, se regula desde lo más ambiguo como "las conductas de degradación visual del espacio" hasta conductas concretas como cantar por la calle "después de las 11 de la noche" o incluso escupir (capítulo 6 - Artículo 38), conducta "incívica" por lo que te pueden caer 50 euros de multa.

Sin embargo, para el caso que aquí nos ocupa, es realmente desesperanzador el capitulo 8 donde nos percatamos que no hay ni un viso descriminalizador del "Top Manta". Se continua criminalizando la venta callejera y en esta misma línea, más grave incluso, es que también se penaliza "colaborar" con los manteros. Se contemplan multas de hasta 500 euros tan solo por hacer acompañamiento de los manteros o avisarles de la presencia de la policía, por lo que, sin temor a equivocarnos, estamos hablando de una norma que criminaliza la solidaridad y premia la indolencia ciudadana.

A la decepción respecto al continuismo de la Ordenanza Cívica se suma el papel activo del Ayuntamiento en uno de los procesos más efectivos a la hora de desarticular a los colectivos irregulares que luchan por permanecer en La Rambla como ha sido, paradójicamente, el intento de cooptación política del Sindicato Mantero, a través de los sucesivos intentos por regular su actividad. Tal parece que aquí el gobierno de "los comunes" continua la línea paradigmática del gobierno del 
tripartito que gobernó Cataluña durante los años 2003 y 2006, que consiguió la regulación de una parte de la prácticas informales en las Ramblas, en aquel entonces centrada en las actividades de las estatuas humanas y los músicos callejeros (Porras, 2016). Inicialmente, gracias a la Ordenanza se regularizó el uso del espacio público en La Rambla, pero desde 2007 se amplió el acuerdo con los trabajadores, sufriendo actualizaciones en cada mandato, como sucedió con el anterior gobierno de CiU, que por medio del Plan Cor, y sin consenso con los artistas, fueron desplazados hacia el final de la Rambla, determinando sus lugares, horarios, requisitos, exigencias, licencias y tasas.

Se estableció una normativa con perfil empresarial, que convierte a cada estatua humana en una empresa registrada en el Censo de empresarios profesionales retenedores. Lo que lleva a tratar a un grupo de artistas, que realizan una misma actividad, como empresas individuales a las que se les exige unas condiciones burocráticas que no todos pueden cumplir, imponiendo situaciones de irregularidad. Un formato de regularización totalmente "exitoso": se redujeron las plazas, las estatuas humanas no tienen injerencia en el proyecto, y son tratados como empresarios (Porras, 2016, pp. 214-220).

No es muy diferente al caso de los músicos de calle, al igual que las estatuas humanas comenzaron a ser reguladas en el distrito de Ciutat Vella desde 2004. Se creó una normativa que determinaba los puntos de interpretación, el mecanismo administrativo para obtener la licencia y los sorteos de los lugares y los horarios. Esta normativa excluyó toda gestión por parte de los músicos. El proyecto, administrado por el Centro cívico del Convento de San Agustín ha determinado desde el inicio la relación entre el Ayuntamiento y los músicos. Sin embargo, la normativa no ha respetado las realidades de los músicos. Ni los turnos ni los espacios, fueron acordados con los músicos, creando una situación en la que muchos tienen que desobedecer la normativa para poder llegar a los ingresos necesarios. La resolución de los conflictos que puedan tener los músicos entre sí o en su entorno está totalmente fuera de sus manos. Si un vecino se queja de la música, se cancela el punto de ejecución, perjudicando a todo el colectivo, "infantilizándoles" en su capacidad de negociación y resolución de conflictos. Sumado a que la aplicación de la justicia está en manos de la Guardia Urbana, que tiene a su discreción toda la libertad que le dan la normativa de músicos de calle y la Ordenanza de Civismo.

Dentro de esta lógica "emprendurista", al Sindicato Popular de Vendedores Ambulantes se le ha querido enrolar en un marco regulatorio basado en la competencia entre sus miembros, y a espaldas de la lógica colectivista que les caracteriza. Los procesos de regularización han tenido algunas constantes a lo largo de las últimas décadas, desde el gobierno del tripartito con la regularización de las actividades de estatuas humanas y chatarreros en la rambla, así como la constante persecución de lateros $^{18}$ tanto en La Rambla, como en el resto del distrito de Ciutat Vella. Pero, sin lugar a dudas, el proceso de regularización con mayor impacto político en la ciudad ha sido el de los manteros.

Principalmente, porque el Sindicato Popular de Vendedores Ambulantes está ejerciendo el papel de los "nuevos sindicatos", reivindicación laboral sumada a luchas transversales que existen en la ciudad: racismo, clasismo, política migratoria, interculturalidad, uso de la calle, turismo, entre otras. El proceso de regularización de los vendedores ambulantes inicia con la entrada del Ayuntamiento actual, que convoca a una mesa de negociación, en la cual deciden no participar los comerciantes establecidos, ya que "no iban a sentarse a negociar con mafiosos" haciendo referencia a los manteros.

Después de algunos acercamientos infructuosos se inició el proceso de constitución de una cooperativa con el objetivo de dar soluciones de trabajo a los manteros, tal como fue comunicado a la gente del Sindicato. Sin embargo, durante las negociaciones, el gobierno no perdió la oportunidad de

18 Vendedores ilegales de latas de cerveza en la calle. Normalmente procedentes de Paquistán, India o Bangladesh. 
instrumentalizar políticamente la cooperativa y en vez de acceder al reparto de las plazas a través de manera asamblearia como pedían los voceros del Sindicato se sugirió que fueran los mismos voceros quienes accedieran al beneficio lo cual fue interpretado por estos como un mecanismo de "compra de voluntades".

La renuencia a participar en este juego político por parte del Sindicato derivó en la entrega del proyecto de cooperativa a otras entidades de apoyo a "la comunidad senegalesa". Entidades que no representan la lucha política de los manteros. Al final, de un proyecto que originalmente contemplaba la contratación de 40, tan solo terminaron accediendo 4 manteros. Se trata de una cifra pírrica en comparación con los cerca de 1,000 vendedores ambulantes de la ciudad. Este es un ejemplo de cómo cuando los procesos de regularización no son consensuados con las poblaciones afectadas sino manipulados institucionalmente, pueden verse transformados en mecanismos de vendetta política, ideología empresarial y falsa solución de problemáticas socio-urbanas.

Así, parece que se repite lo que históricamente afectó a los chatarreros, músicos y estatuas humanas, la fractura de un colectivo por medio del mejoramiento de las condiciones de un pequeño grupo, sin que incluso se otorgue la posibilidad de autogestionar la creación de la cooperativa. Aunque algunos no les parezca así, el gobierno actual está desperdiciando el talante negociador de los manteros y la voluntad expresada por regular su actividad en conjunto con las instituciones. Parece ser que la única puerta que deja abierta esta administración es la de la desobediencia, la cual, no puede ser considerada ilegítima cuando se trata de la obtención de los medios materiales para el mantenimiento de la vida en unas condiciones mínimas de dignidad.

En algunos momentos parece que la regularización tiene toda la buena intención del "Ayuntamiento del cambio", sin embargo, se termina imponiendo la inercia tecnocrática. Es eso, o se considera mejor gestionar "exitosamente" como ya lo han

\section{Regularizar es un proceso delicado y peligroso, siempre se corre el riesgo de seleccionar y fracturar. Por esto es necesario darle más peso a las realidades de los trabajos.}

logrado otras administraciones, desarticulando, para invisibilizar, para olvidar grandes conflictos urbanos. Regularizar es un proceso delicado y peligroso, siempre se corre el riesgo de seleccionar y fracturar. Por esto es necesario darle más peso a las realidades de los trabajos, sumado a todas sus luchas, que a las necesidades tecnócratas de que las competencias urbanísticas no contradigan a las económicas, o a las de migraciones, y que la regulación no solape a la norma, que la norma no contradiga la ley, que la nueva ley no genere disputas con otros grupos parlamentarios, lo que da por resultado que la regulación de la actividad sea incompatible con la vida digna.

\section{Conclusiones}

El espacio público es un concepto paradójico que teóricamente se funda en la igualdad pero que funciona en base a la exclusión. Así, los espacios públicos son "todas aquellas áreas que están abiertas y son accesibles a todos los miembros del público en una sociedad, en principio, pero no necesariamente en la práctica" (Neal, 2010) por lo tanto: ¿quienes son "los todos" cuando hablamos de que el espacio público es "de todos"? Como un "ideal normativo", el espacio público es producto de cierto imaginario social antes que un lugar empíricamente constatable. El espacio público aparece representado insistentemente como un lugar desconflictivizado.

El discurso que legitima e incluso eleva el espacio público a la categoría de "valor" está estructurado 
de tal manera que oculta a la vez que resuelve "mágicamente" las contradicciones que se dan en él. Los conflictos sociales profundos que repetidamente se vuelven a presentar en la realidad práctica de espacios públicos concretos son presentados como consecuencia de determinadas fórmulas urbanísticas, y así mismo la solución de tales problemas "es vendida" como una "solución urbanística", fórmula que incluso se encuentra en autores de indudable valor como Jan Gehl (2001). Por otro lado, lo que subyace en el discurso prefabricado acerca del espacio publico es "el carácter consensualista" del concepto de "Esfera Pública" de Habermas (1962) cuyo origen es evidentemente burgués (Fraser, 1990).

Esta inoculación de los elementos ideológicos de la esfera pública como característicos de "la calle" es a grandes rasgos lo que Manuel Delgado denominaría "ciudadanismo" (2016), es decir, la elevación a norma del ideal burgués de un espacio desconflictivizado y civilizatorio, que mágicamente haga desaparecer todas las desigualdades sociales "reales" gracias a las habilidades deliberativas de sujetos racionales capaces de superar sus diferencias mediante el diálogo. Todo en consonancia con los valores de las democracias liberales. Aunque Habermas no situó "la esfera pública" en espacios concretos es posible situar históricamente a que espacios se refería a partir de sus propios ejemplos: clubes literarios, asociaciones filantrópicas, cafés, salones de té y redacciones de periódicos.

La calle, con su caótica deriva no parece el espacio ideal para situar la mítica esfera pública. Así, los que quieren transformar la calle en espacio público entendido este desde el consensualismo liberal habermasiano se encuentran con el no menor de los problemas de tener que hacer "como sí" las desigualdades no existiesen en la sociedad y por lo tanto "en la calle", para que de esta manera la calle se transfigure en "espacio público", aquello que la calle debe ser según el ideal normativo consensualista. Cuando este ideal no se alcanza "por las buenas" las fuerzas coercitivas del Estado se ponen "manos a la obra" para reforzar con represión su labor civilizadora.

Igualmente problemática es otra característica central atribuida al espacio público: su supuesta "titularidad pública" que suele implicar que lo propio del espacio público es que constituyentemente sea propiedad del Estado. El Estado, por lo tanto, debería garantizar la propiedad pública de aquellos espacios que en teoría son comunes, así como su gestión y regulación como ámbito vedado para intereses privados, siguiendo la disposición ciudadana a ser la legítima beneficiaria de la calle. Sin embargo, son muchos los ejemplos que desmienten esta idealización: existen múltiples formas de cooptación de lo público por parte del sector privado. La tensión realmente existente entre lo público y lo privado es estructural a la lógica mercantilista del urbanismo en las democracias liberales y capitalistas. Son muchos los casos de ciudades donde prevalecen los intereses empresariales por sobre el carácter público, de los cada vez más utópicos espacios "públicos" de las ciudades (Jackson, 1998; Aricó et al., 2016).

Frente a la ola privatizadora de ciudades como Barcelona, para la opinión dominante es la informalidad urbana aquella señalada como "invasora". Lo informal es identificado ahí donde los sectores más vulnerables se auto-organizan. Sus prácticas parecen espontáneas "a primera vista" a pesar de estar profundamente organizadas. Las suelen llevar a cabo actores sociales ubicados en la parte baja de la pirámide social: pobres, inmigrantes, prostitutas, niños y jóvenes, percibidos por el imaginario hegemónico como actores sociales naturalmente excluibles del espacio. Estos grupos hacen de la calle su refugio, campo de juegos o medio de subsistencia. Se organizan como clanes, familias, pandillas, cuadrillas y otras formas de organización social no burocrática. Su relación con el Estado es ambigua pero no necesariamente inexistente. Las reglas que los rigen no suelen estar escritas y su conocimiento es más un saber-hacer que un saber enciclopédico. 
El espacio público se construye gracias a colectivos que llevan a cabo prácticas como mercadillos callejeros, recolección autónoma de desechos y chatarra, que autoconstruyen la infraestructura urbana, plantan huertos urbanos, hacen fiestas callejeras o se despliegan en microscópicos carnavales espontáneos con el simple encuentro lúdico en la calle de aquellos que se encuentran bajo tutela o sospecha de los adultos o el Estado. La irrupción e inmediata censura de usos y prácticas "no regladas" en el espacio público revela que la esfera pública está basada en la confrontación entre diversos "públicos" que pugnan por el espacio. Es decir, el espacio público es la forma urbana que adopta un conflicto social estructural y a su vez es el escenario donde se manifiestan aquellas disputas concretas por el espacio público de la ciudad. El espacio público es un subproducto del conflicto social pero a su vez es el espacio sobre el cual se dirimen tales conflictos. La calle es el escenario y la obra donde se despliega el conflicto. En este contexto, la informalidad es uno de los personajes principales de este conflicto urbano escenificado, a la vez que un producto de los conflictos sociales estructurales que dan a luz a un espacio público concreto.

\section{Referencias bibliográficas}

Acebillo, J.A. (1999) “El Modelo Barcelona desde el punto de vista urbanístico. Espacio urbano y complejidad", en MARAGALL, P. (ed.) Europa próxima: Europa, regiones y ciudades, Barcelona: Edicions Universitat de Barcelona.

Ajuntament De Barcelona (2005/2018) Ordenanza de medidas para fomentar y garantizar la convivencia ciudadana en el espacio público de Barcelona. Acuerdo del Consejo Plenario de 23-12-2005 (Texto consolidado. Incluye las modificaciones Posteriores).

Aricó, G. Et al. (2016) "La salvaguarda ininterrumpida del poder de clase. Una visión alternativa a la "teoría de las etapas" en el urbanismo barcelonés". En: Aricó, G. Et al. (ed.), Barrios Corsarios. Memoria histórica, luchas urbanas y cambio social en los márgenes de la ciudad neoliberal. Barcelona: OACU/Pollen edicions.

Arrighi, G. (1994). El largo siglo XX. Barcelona: Akal. 1999.

Benjamin, W. (1982) Obra de los pasajes, vol. 1. Madrid: Abada. 2013.

Berman, M (1982). Todo lo sólido se desvanece en el aire. México: Siglo XXI. 2013.

Butler, J. (1993). Cuerpos que importan: sobre los límites materiales y discursivos del sexo. Barcelona: Paidós.

Capel, H. (2006) El modelo Barcelona: un examen crítico. Barcelona: Ediciones del Serbal. 2011.

Careri, F. (2013) Walkscapes. El andar como práctica estética. Barcelona: Gustavo Gili. 2014.

Careri, F. (1 de Diciembre del 2016). Errare Humanum Est. En H. ESPINOSA. Seminario permanente OACU-UB. Facultad de Geografía e Historia. Universidad de Barcelona. España.

Cerdá, I. (1859) Teoría de la Construcción de las Ciudades. Cerdá y Barcelona, vol.1. Madrid: Ministerio para las Administraciones Públicas/ Ajuntament de Barcelona, 1991.

Cócola, A. (2011) El Barrio Gótico de Barcelona. Planificación del Pasado e Imagen de Marca. Barcelona: Madroño. 2014.

De Certeau, M. (1980) La invención de lo cotidiano, Tomo 1: Artes de Hacer. México, D.F/ Guadalajara: Universidad Iberoamericana/ ITESO. 2000.

Delclós, C. (2016) La incapacidad de la izquierda para gestionar la economía informal. En CTXT. Núm. 83.

Delgado, M. (2011) El espacio público como ideología, Madrid: La Catarata.

Delgado, M. (2016) Ciudadanismo, Madrid: La Catarata.

Delgado, M. (15 de Agosto del 2016). El ciudadanismo y el nuevo municipalismo en España. Seres Urbanos. Diario El País. Recuperado de: https:// 
blogs.elpais.com/seres-urbanos/2016/08/index. html

Espinosa, H. y Porras, J. (28 de septiembre del 2016). No es una política racista, es clasismo institucionalizado. Periódico Diagonal. Recuperado de: https://www.diagonalperiodico. net/global/31630-no-es-politica-racista-esclasismo-institucionalizado.html

Espinosa, H. y Porras, J. (11 de Noviembre del 2016). Crónica del fracaso continuado de la regulación del trabajo callejero en Barcelona. Recuperado de: https://www. diagonalperiodico.net/libertades/32233regular-para-olvidar-cronica-del-fracasocontinuado-la-regulacion-del-trabajo

Espinosa, H. y Mansilla, J. (24 de Agosto del 2017). La paradoja de los bolardos como elementos de control. El Diario.es. Recuperado de: https:// www.eldiario.es/catalunya/opinions/paradojabolardos-elementos-control_6_679342068.html

Espinosa, H. (2017) Les vertus de la violence. La légitimation d'un projet de rénovation urbaine par le néo-hygiénisme. Espaces et sociétés, (3), 173-186.

Fernández, M. (2014) Matar al Chino. Entre la revolución urbanística y el asedio urbano en el barrio del Raval de Barcelona, Barcelona: Virus.

Fraser, N. (1990) Rethinking the public sphere: A contribution to the critique of actually existing democracy. Social Text, 25/26, 56-80.

Gehl, J. (2001) Life between buildings. Copenhagen: The Danish Architectural Press.

Habermas, J. (1962) Historia y crítica de la opinión pública, Barcelona: Gustavo Gili. 1982.

Jackson, P. (1998). Domesticating the street. The contested spaces of the High Street and the mall. In Nicholas Fyfe (Ed.), Images of the street. Planning, identity and control in public space (pp. 176-191). London: Routledge.
Jones, O. (2011). Chavs: La demonización de la clase obrera. Madrid: Capitán Swing. 2013.

Lefebvre, H. (1974) La producción del espacio, Madrid: Capitán Swing. 2013.

Montaner, J.M. (1992) "El modelo Barcelona”. En: Elisava. Temas de Diseño. Num. 7. El diseño en los Juegos Olímpicos: un legado para Barcelona. Barcelona: Elisava. Escuela Universitaria de Diseño e Ingeniería de Barcelona.

Neal, Z. P. (2010). Locating public space. En Anthony M. Orum \& Zachary P. Neal (Eds.), Common ground? Readings and reflections on public space (pp. 1-10). New York: Routledge.

Parra, B. (25 de Mayo del 2016). Barcelona destinará 50.000 euros de la tasa turística para subvencionar el Tast de La Rambla. El Mundo. Recuperado de: https://www.elmundo.es/catal una/2016/05/25/5745b76622601d40188b45f0. html.

Porras, J. (2016) “Otros trabajos y otros trabajadores en Barcelona", Polis, Revista Latinoamericana, Volumen 15, No 45, p. 211-234.

Saiz, Y. (9 de Junio del 2016) Arranca 'Tast a la Rambla', la fiesta gastronómica de Barcelona. La Vanguardia. Recuperado de: https://www.la vanguardia.com/comer/al-dia/20160609/ 402390605454/tast-a-la-rambla-2016.html

Valentí, R. (22 de Marzo del 2013) Las sillas de alquiler de La Rambla. Recuperado de: http:// eltranvia48.blogspot.com/2013/03/las-sillasde-alquiler-de-la-rambla.html.

Vasallo, B. (3 de Abril del 2016) Del pornoburka al purplewashing, los trucos más sucios contra el feminismo (Entrevista con Víctor Lenore). El Confidencial. Recuperado de: https://www. elconfidencial.com/cultura/2016-04-03/ del-pornoburka-al-purplewashing-los-trucosmas-sucios-contra-el-feminismo_1170764/ 